\title{
STATISTICAL DOWNSCALING AND PROJECTION OF FUTURE TEMPERATURE AND PRECIPITATION CHANGE IN GANDAKI BASIN
}

\author{
Dibas Shrestha $^{1 *}$, Shankar Sharma ${ }^{1}$, Sandeep Bhandari ${ }^{2}$, Rashila Deshar $^{3}$ \\ ${ }^{I}$ Central Department of Hydrology and Meteorology, Tribhuvan University, Kathmandu, Nepal \\ ${ }^{2}$ Institute of Engineering, Pulchowk Campus, Tribhuvan University, Lalitpur, Nepal \\ ${ }^{3}$ Central Department of Environmental Science, Tribhuvan University, Kathmandu, Nepal \\ "Corresponding author: st.dibas@yahoo.com
}

(Received: September 23, 2020; Revised: December 28, 2020; Accepted: March 30, 2021)

\begin{abstract}
Understanding the present and future spatial and temporal variations of precipitation and temperature is important for monitoring climate-induced disasters. Satellite and global reanalysis data can provide evenly distributed climate data; however, they are still too coarse to resolve fundamental processes over complex terrains. The study applies global climate model CGCM4/CANESM2, to project future maximum temperature, minimum temperature, and precipitation across the cross-section of the Gandaki River basin, Nepal. Large scale atmospheric variables of the National Centre for Environmental Prediction/National Centre for Atmospheric Research reanalysis (NCEP/NCAR) datasets are downscaled using Statistical Downscaling Model (SDSM) under different emission scenarios. For the variability and changes in maximum temperature $\left(T_{\max }\right)$, minimum temperature $\left(T_{\min }\right)$, and precipitation for future periods $(2020 \mathrm{~s}, 2050 \mathrm{~s}$, and 2080s), three different scenarios RCP2.6, RC4.5, and RCP8.5 of CGCM4 model were performed. The study revealed that both the temperature and precipitation would increase for three RCPs (representative concentration pathways) in the future. The highest increase in precipitation was found in the arid region compared to humid and sub-humid regions by the end of 2100. Similarly, the increase in mean monthly $\mathrm{T}_{\min }$ and $\mathrm{T}_{\max }$ was more pronounced in Jomsom station than Baglung and Dumkauli stations. Overall, a decrease in summer temperature and increase in winter temperature was expected for future periods across all regions. Further, spatial consistency was observed for $T_{\max }$ and $\mathrm{T}_{\min }$, whereas spatial consistency was not found for precipitation.
\end{abstract}

Keywords: Model, Nepal, Prediction, Precipitation, RCP

\section{INTRODUCTION}

The global near-surface mean air temperature has increased by $0.85^{\circ} \mathrm{C}$ over $1880-2012$ and is expected to increase between 1.4 and $5.8^{\circ} \mathrm{C}$ by the year 2100 (IPCC, 2013). The rising in temperature leads to a large impact on the precipitation pattern, melting of snow and ice, and increases evaporation, altering soil moisture and runoff. As precipitation is a fundamental component in the water cycle, its understanding and a comprehensive outlook are essential for managing water systems under changing climate (Schneider et al., 2016; Daly et al., 2017). Climate change has amplified the extreme precipitation events, which has become more intensive recently. Moreover, these extreme weather events can globally lead to several social, economic, and environmental problems (Cavalcante et al., 2020). Global mean surface temperatures are projected to increase by $0.3-1.7^{\circ} \mathrm{C}, 1.1$ to $2.6^{\circ} \mathrm{C}, 1.4-3.1^{\circ} \mathrm{C}$, and $2.6-4.8^{\circ} \mathrm{C}$ under RCP2.6, RCP4.5, RCP6.0, and RCP8.5, respectively, during 20812100 (Collins et al., 2013). Moreover, global warming will accelerate the frequency and magnitudes of ongoing climatic extremes (Karki et al., 2017).

Consistent with the global pattern, South Asia has experienced several climatic extremes, and such extremes are anticipated to be more frequent in the future (Klein
Tank et al., 2006). Nepal is a South Asian mountainous country experiencing a high rate of temperature increase, changing precipitation patterns, with frequent and severe occurrences of climate-induced disasters, such as landslides, glacial lake outburst floods, flash floods, drought (Khadka et al., 2018; Sharma et al., 2020a, Hamal et al., 2020a). Thus, understanding the present and future spatial and temporal variations of precipitation and temperature is important for monitoring climate-induced disasters (Bhattarai, 2015; Maharjan \& Regmi, 2015).

Furthermore, such information will be vital for long-term planning of mitigation and adaptation strategies at regional and national levels (Frias et al., 2012). The availability of high spatial and temporal resolution climate data is essential for climate studies. However, in Nepal, the climate monitoring stations are sparsely and unevenly distributed; denser in lowlands and sparse in mountainous areas (Kansakar et al., 2004; Hamal et al., 2020b; Sharma et al., 2020b). Moreover, the existing stations in highelevation areas are situated at the valley bottom and may not present the area's actual climatology (Sharma et al., 2020c). Thus, our knowledge of the climate at high elevations, where the hazards are frequent, is still limited.

Satellite and global reanalysis data can provide evenly distributed climate data; however, they are still too coarse 
to resolve fundamental processes over complex terrains (Shrestha et al., 2012; Faiz et al., 2018; Sharma et al., 2020c). Further, general circulations model (GCMs) can estimate future climate change based on these reanalysis datasets (Koukidis \& Berg, 2009; Khadka \& Pathak, 2016). Despite the availability of GCMs output as the most widely used modeling results, this information cannot be used directly due to its course spatial resolution. Thus, the downscaling model is required for converting the coarser spatial resolution of the GCMs output into a fine resolution climatic output variable. There are mainly two techniques to downscale the GCMs, i.e., Dynamical Downscaling (DD) and Statistical Downscaling (SD). Statistical Downscaling Model (SDSM) is a hybrid of a regression method and a weather generator (Koukidis \& Berg, 2009; Mahmood \& Babel, 2013). Several previous studies have shown that SDSM method has superior capability and is suitable for the study region (Sigdel \& Ma, 2016).

Nepal's climate is dominated by the southeasterly monsoon system and occasionally from the Arabian Sea (Hamal et al., 2020c; Sharma et al., 2020d). Due to the sharp spatial and temporal variations in rainfall and temperature across the cross-section of Nepal, the pattern of rainfall and temperature varies in both north-south and east-west directions (Shrestha et al., 2017, 2012, 2000; Pokharel et al., 2019). Moreover, a large variation of temperature and precipitation occurs even over small distances due to highly undulating surface topography with high mountains and deep valleys. Although there has not been comprehensive research in Nepal for temperature and precipitation, previous analyses considerably do not address the issue of future projection.

A recent study by MoFE (2019) predicted that mean temperature could rise by $0.9-1.1^{\circ} \mathrm{C}$ and $1.3-1.8^{\circ} \mathrm{C}$ for 2016-2045 and 2036-2065, respectively. Khadka et al. (2014) used multiple GCMs scenarios. They showed that average temperature and precipitation would increase in the future at the rate of $0.025^{\circ} \mathrm{C} /$ year and $4.7 \mathrm{~mm} / \mathrm{year}$, respectively, in the Tamakoshi basin of Nepal. Similarly, a study by WECS (2014) suggested that annual mean temperature will increase by $1.4^{\circ} \mathrm{C}, 1.6^{\circ} \mathrm{C}$ and $2.3^{\circ} \mathrm{C}$ in the 2030s, 2040s, and 2050. Annual precipitation will change by $-3,+2$, and $+5 \%$ during the same period compared to 1981-2010 in the Koshi river basin. In Marshyangdi river basin (Central Nepal), the annual average of maximum temperature was predicted to increase by $0.82^{\circ} \mathrm{C}, 1.35^{\circ} \mathrm{C}$, and $2.29^{\circ} \mathrm{C}$ by $2090 \mathrm{~s}$, while the annual average of minimum temperature was projected to increase by $0.87^{\circ} \mathrm{C}, 1.44^{\circ} \mathrm{C}$ and $2.43^{\circ} \mathrm{C}$ by 2090s for RCP2.6, RCP4.5 and RCP8.5, respectively (Khadka \& Pathak, 2016). Sigdel and Ma (2016) have also predicted a significant increase in precipitation between $11.68 \%$ and $13.75 \%$ across Nepal's western region in the 2050s. Though several studies on the future projection of temperature or rainfall using SDSM have been done in Nepal, no studies were conducted in Nepal using the latest version of CGCM4 under the latest forcing scenario. The CGCM2/CANESM2 model is considered improved over the previous version. Hence, this study aims to analyze the future changes in temperature and precipitation over three climatic regions of the Gandaki River Basin (GRB), Central Nepal, under different RCP scenarios.

\section{MATERIALS AND METHODS}

\section{Study area}

Nepal is a South Asian mountainous country located between $26.36^{\circ} \mathrm{N}-30.45^{\circ} \mathrm{N}$ and $80.06^{\circ} \mathrm{E}-88.2^{\circ} \mathrm{E}$ covering an area of $147,641.28 \mathrm{~km}^{2}$ (Fig. 1). Within a short latitudinal range, the country features extreme topography with numerous ecological zones often summarized in three bands: the tropical southern plain-the Terai; the temperate Middle-Mountains, and the polar High Himalaya to the north, and each being associated with an extremely complex climatic variation (Karki et al., 2015; Karki et al., 2017; Talchabhadel \& Karki, 2019). We have selected the Gandaki River Basin, a transboundary basin lying north-south in the central Himalayan region for the current study. It extends from China in the north, through Nepal, to India in the south and is bounded by the Karnali basin to the west and the Koshi basin to the east, featuring wide variation in elevation and climate (Fig. 1a). The basin has a total drainage area of $46,300 \mathrm{~km}^{2}$ that covers $72 \%$ in Nepal, $18 \%$ in India, and $10 \%$ in China. The Gandaki River is also known as the Narayani in the plains of Nepal and as the Gandak in India, where it joins the Ganges (Ganga) at Hajipur near Patna. It has seven major tributaries (the Kali Gandaki, Seti Gandaki, Madi, Marsyangdi, Daraudi, Budhi Gandaki, and Trishuli), of which all except the Daraudi and Madi have catchment areas with glaciers. There are 1,710 glaciers in the upstream catchments (as of 2005), with an area of 2,285 $\mathrm{km}^{2}$ and estimated ice reserves of $194 \mathrm{~km}^{3}$ (Bajracharya \& Shrestha 2011).

In this study, we have selected three stations representing a cross-section across the Gandaki basin, namely Dumkauli (Nawalparasi) in the Terai, Baglung in the Mountains, and Jomsom in the Upper Mountains (Figs. 1a and $b$ ). Based on rainfall distribution and agro-ecological classification, Jomsom, Baglung, and Dumkauli station fall under the arid, sub-humid, and humid regions, respectively (Figs. 1c, d and e). A similar approach was previously applied in the study of Williams et al. (2004). The geographic location of the station is presented in Table 1 and Fig. 1a.

\section{Data}

The observed daily precipitation and temperature data for the three stations (Jomsom, Baglung, and Dumkauli) 
between 1981 and 2005 were obtained from the Department of Hydrology and Meteorology, Government of Nepal. The missing data of 1 day or 2 days were replaced by the average precipitation values of neighboring stations using a single best estimator method
(Eischeid et al., 1995). Further, the observed daily precipitation and temperature data were merged in a single file from 1981 to 2005 for the predictor selection process.

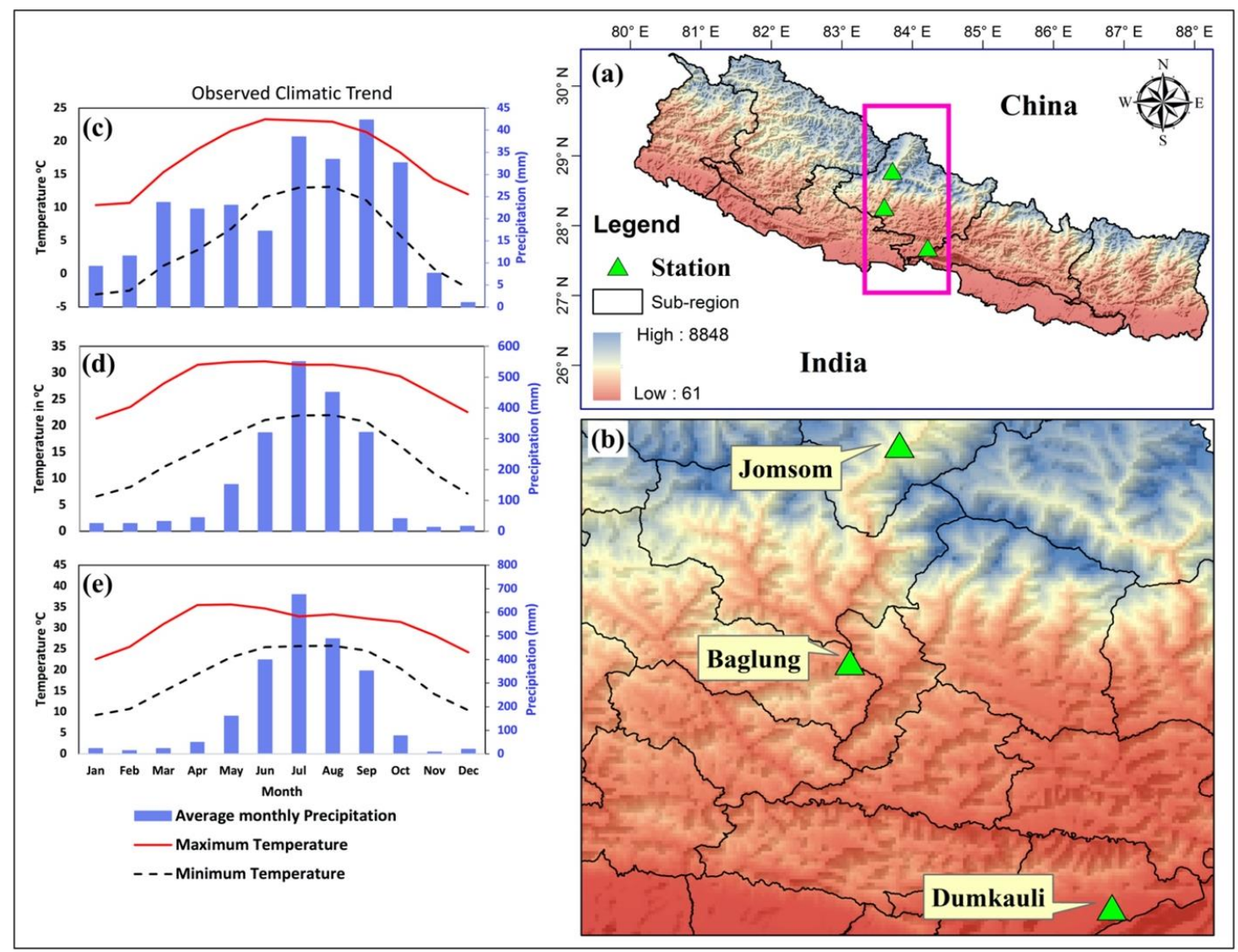

Fig. 1. (a, b) Study areas and location of selected three stations, monthly precipitation, and temperature cycle of (c) Jomsom station, (d) Baglung station, and (e) Dumkauli station

Table 1. Location of study stations

\begin{tabular}{|l|l|l|l|l|l|}
\hline Station Name & Station No. & Latitude & Longitude & Elevation (asl) $(\mathrm{m})$ & Climate \\
\hline Jomsom & 601 & $28^{\circ} 47^{\prime}$ & $83^{\circ} 43^{\prime}$ & 2744 & Arid \\
\hline Baglung & 605 & $28^{\circ} 16^{\prime}$ & $83^{\circ} 36^{\prime}$ & 984 & Sub-humid \\
\hline Dumkauli & 706 & $28^{\circ} 41^{\prime}$ & $83^{\circ} 13^{\prime}$ & 154 & Humid \\
\hline
\end{tabular}

The re-analysis data set from the National Centers for Environmental Prediction (NCEP)/National Center for Atmospheric Research (NCAR) (Kalnay et al., 1996) were also used in this study. The data set was available daily during the period 1961-2005 at a spatial scale of $2.8^{\circ} \times 2.8^{\circ}$ with 26 atmospheric variables. Global Climate Model (GCM) output data set with three forcing scenarios RCP8.5 (high greenhouse gas emission scenarios), RCP 4.5 (moderate greenhouse gas emission scenarios) and RCP2.6 (low greenhouse gas emission scenarios) derived from the CGCM4/CANESM2 climate model, which has the same grid resolution as NCEP/NCAR predictor variable of 128 X 64 grid boxes. The transformed GCM data for 1961-2099 was directly downloaded from (http://www.cics.uvic.ca/scenarios/sdsm/select.cgi).

The widely used statistical downscaling model Statistical Down Scaling Model (SDSM) developed by Wilby et al. (2002) has been used to downscale GCM data for selected three stations. This model used a combination of Multiple Linear Regression (MLR) and Stochastic Weather Generator (SWG) methods. 
In the current study, The MLR was used to establish an empirical relationship between predictors and predictands of interest to generate regression parameters, whereas SWG was applied to simulate up to 100 daily time-series from predictors of NCEP/NCAR and GCMs based on these regression parameters. This method was adopted from Mahmood and Babel (2014). Further, downscaling of the Maximum Temperature $\left(\mathrm{T}_{\max }\right)$, Minimum Temperature $\left(\mathrm{T}_{\min }\right)$, and Precipitation (PRECP) was done using SDSM; first we checked the quality, transformation, and screening of probable predictors, then we calibrated the monthly sub-model using station scale of $\mathrm{T}_{\max }, \mathrm{T}_{\min }$ and PRECP data sets and selected predictors of NCEP/NCAR. To generate the present and future time series for $\mathrm{T}_{\max }, \mathrm{T}_{\min }$, and PRECP from the gridded data sets (NCEP/NCAR and GCMs (CGCM4/CANESM2)), we applied Statistical Analysis for downscaled $\mathrm{T}_{\max }, \mathrm{T}_{\min }$, and PRECP at each station using SDSM.

To discard the missing records and outliers in the observed data sets, a quality control function was performed in SDSM. Then screen variable operation was applied to select appropriate sets of observed predictors from the suite of NCEP/NCAR reanalysis data sets based on scatter plots, correlation, partial correlation statistics, and $p$-value (Wilby \& Dawson, 2007). For the calibration and validation, the observed station scale data $\left(\mathrm{T}_{\max }, \mathrm{T}_{\min }\right.$, and PRECP) were divided into two periods, i.e., from 1981 to 1996 for calibration and from 1997 to 2005 for validation.

SDSM offers three different sub-models: monthly, seasonal, and annual for the downscaling of predictands ( $\mathrm{T}_{\max }, \mathrm{T}_{\min }$, and PRECP) from the large-scale predictors (Koukidis \& Berg, 2009; Mahmood \& Babel, 2013). The monthly sub-model derives 12 different regression equations (one for each month), whereas the seasonal submodel generates four different regression equations (one for each season), and the annual sub-model creates a single regression equation for all 12 months having same model parameters. A monthly sub-model was used in this study due to significant monthly variations in $\mathrm{T}_{\max }, \mathrm{T}_{\min }$, and PRECP at different stations within the study region. Moreover, SDSM provides two methods for optimization; Dual Simplex and Ordinary Least Squares (Wilby \& Dawson, 2007). Although both methods provide comparable results, we chose Ordinary Least Squares, as this method provides more efficient results and were suitable for the study region's topographic nature.

Further, in the validation process, the same predictors' variables screened in respective stations were used in the next time frame to validate the calibrated model. Furthermore, biases were checked and corrected before the generation of future and present time series for temperature and precipitation data. Eqs (1) and (2) were used for the bias correction of daily temperature $\left(\mathrm{T}_{\max }\right.$ and $\mathrm{T}_{\min }$ ) and precipitation (PRECP) data, respectively.

$$
\begin{aligned}
& T_{c}=T_{u c}-\left(T_{m}-T_{o}\right) \\
& P_{c}=P_{c} \times \frac{P_{o}}{P_{m}}
\end{aligned}
$$

Where, $\mathrm{T}_{\mathrm{c}}$ and $\mathrm{P}_{\mathrm{c}}$ are the corrected future daily time series of temperature and precipitation data, respectively. $\mathrm{T}_{\mathrm{uc}}$ and $\mathrm{P}_{\mathrm{uc}}$ are uncorrected future daily time series of temperature and precipitation data downscaled by SDSM, respectively. $T_{m}, P_{m}$ and $T_{o}, P_{o}$ is the long term mean monthly temperature and precipitation data during control simulation and observed period (i.e., 1981-2005).

After bias correction, systematic daily time-series data representing the present climate from screened sets of NCEP/NCAR predictors were generated through a weather generator. The downscaled data were then compared with observed records to confirm its accuracy. Finally, future time series of $\mathrm{T}_{\max }, \mathrm{T}_{\min }$, and PRECP were simulated on daily time-step under RCP2.6, 4.5, and 8.5 emission scenarios. The performance of SDSM for the future along with downscaled results were discussed for future periods; 2020s (2010-2039), 2050s (2040-2069), and 2080s (2070-2100) under RCP2.6, RCP4.5, and RCP8.5 emission scenarios, respectively. Additionally, various statistical operations were performed based on a downscaled projected time series of $\mathrm{T}_{\max }, \mathrm{T}_{\min }$, and PCP to predict the changes in the study area's observed climatology

\section{RESULTS AND DISCUSSION}

\section{Screening of predictors}

Screening of suitable predictors for downscaling predictands is one of the most critical steps in statistical downscaling (Wilby et al., 2002; Wilby \& Dawson, 2007). The predictors can be different for different geographical regions depending on the predictor's properties and the predictand to be downscaled (Anandhi et al., 2008). Both qualitative (e.g., scatter plots) and quantitative (e.g., the value of explained variance for different months; correlation $\left(\mathrm{R}^{2}\right)$ and $p$-values methods were used to identify the most suitable sets of predictors at an individual station. The list of predictors variables selected for this study is shown in Table A1.

\section{Calibration}

The observed data series from 1981-2005 was divided into two sub-periods, i.e., 1981-1996 and 1997-2005, for model calibration and validation. Following the user manual of SDSM 4.2, when using NCEP/NCAR reanalysis data as predictors, a threshold of the wet day was set as $0.3 \mathrm{~mm}$, and fourth root transformation was adopted to convert the original precipitation time-series to a normal distribution (Wilby et al., 2002). 
The ordinary least squares method was used for optimization, whereas no transformation was done in temperature data, although a threshold value of 0 was selected for temperature. The several statistical measures: coefficient of determination $\left(R^{2}\right)$, root mean square error (RMSE), Mean Absolute Percentage Error (MAPE), and Mean Absolute deviation (MAD) are used to compare observed data with downscaled data during the calibration and validation period.

All three stations showed a good correlation (0.99) between observed and downscaled temperature and precipitation data, except the Jomsom station's precipitation correlation. The higher RMSE and MAD values were found at Dumkauli, followed by Baglung and Jomsom stations in precipitation, while all three stations showed similar values for temperature. In general, calibration for $T_{\max }$ and $T_{\min }$ was very satisfactory and consistent for all stations; however, calibration for precipitation was not consistent. This may be related to the large number of zero values entered in the multiple regressions, and the underlying surface factors are not considered in SDSM.

\section{Validation}

The data set between the periods of 1997 to 2005 were used to validate the calibrated model using the same predictors and statistical metrics that have been used for the calibration period. The $\mathrm{T}_{\max }$ and $\mathrm{T}_{\min }$ validation model showed consistent performance over all stations, although the validated model of PRECP was not consistent.

\section{Bias Correction}

Before applying the future downscale $\mathrm{T}_{\max }, \mathrm{T}_{\min }$, and PRECP, we validated the datasets between 1997 and 2005 using equations 1 and 2. Firstly, obtained biases were adjusted to the downscaled daily data by SDSM for 19972005. Secondly, the corrected downscaled data were compared with the observed data using different statistical metrics ( $\mathrm{R}^{2}$, RMSE, MAPE, and MAD) and then further applied to the future downscaled data. Table 2 and Fig. 2 show the statistical analysis between bias-corrected and not corrected precipitation data at Jomsom station. The bias was slightly improved after bias correction with increased $\mathrm{R}^{2}$ and decreased error. It was noted that values of $\mathrm{T}_{\max }$ and $\mathrm{T}_{\min }$ obtained without bias correction were close to the observed data than bias-corrected. The necessity for bias correction for Jomsom precipitation is attributed to the insufficient number of predictor variables screened for the model and the complex nature of the precipitation variable itself (Salzmann et al., 2007).

Table 2. Statistical comparison of PCP before and after bias correction in Jomsom during the validation period

\begin{tabular}{|c|c|c|c|c|c|c|c|}
\hline \multicolumn{3}{|c|}{ Before bias correction } & \multicolumn{4}{c|}{ After bias correction } \\
\hline $\mathrm{R}^{2}$ & RMSE & MAPE & MAD & $\mathrm{R}^{2}$ & RMSE & MAPE & MAD \\
\hline 0.90 & 0.15 & 20.06 & 0.12 & 0.95 & 0.09 & 16.48 & 0.08 \\
\hline
\end{tabular}

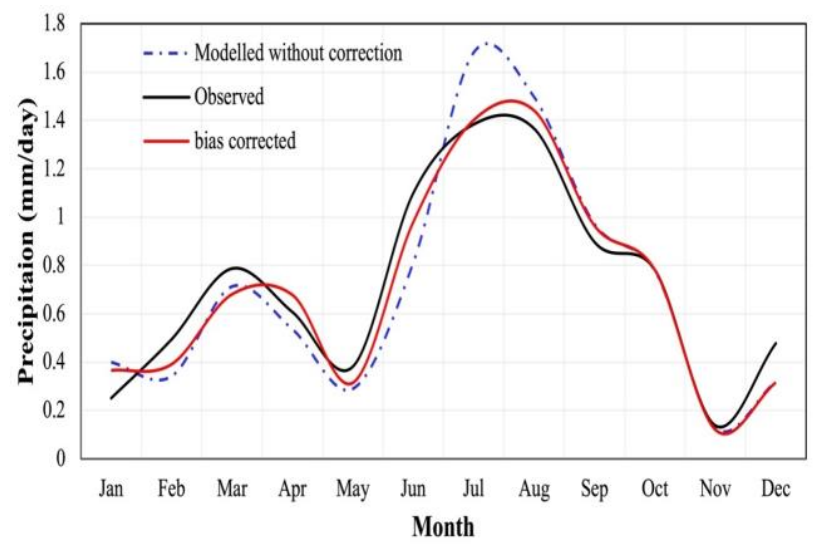

Fig. 2. Bias corrected values with modeled and observed precipitation (PRECP) for Jomsom station during 1997-2005

Future projection of precipitation (PRECP) and temperature $\left(\mathbf{T}_{\max }\right.$ and $\left.\mathbf{T}_{\min }\right)$

Future scenarios of daily temperature $\left(\mathrm{T}_{\max }\right.$ and $\left.\mathrm{T}_{\min }\right)$ and precipitation (PRECP) were generated under RCP2.6,
RCP4.5, and RCP8.5 forcing scenarios for 2010-2100. The future period was divided into the 20s (2010-2039), 50s (2040-2069), and 80s (2070-2100) to study the changing pattern of temperature and precipitation concerning the base period (1981-2005). For the analysis, daily temperature and precipitation values were averaged to obtain annual and monthly values at each station.

\section{Future change in precipitation}

The precipitation distribution of Nepal showed a strong seasonal variation with a large amount of rainfall observed in the summer season, while other seasons remained relatively dry. Understanding future seasonal and annual behavior is, therefore, very important to get a deeper insight into future precipitation changes in the Himalayas. The future changes in seasonal and annual precipitation compared to the base period 1981-2005 under RCP2.6, RCP4.5, and RCP8.5 scenarios for three regions of Nepal are shown in Fig. 3. The seasonal changes across three study regions showed a noticeable difference in trend and magnitude under different RCP scenarios. The enormous change in precipitation is 
expected during the winter season for all future periods in Jomsom (Figs. 3a, b, and c). The seasonal changes in Jomsom were marked up in the winter season for future periods $20 \mathrm{~s}, 50 \mathrm{~s}$, and $80 \mathrm{~s}$ with values $60.5 \%, 84.3 \%$, and $111.9 \%$, respectively, while a decrease in seasonal rainfall during spring. In contrast, Baglung will experience an increase in rainfall during winter and spring season with values $7.4 \%, 44.9 \%$, and $70.3 \%$, during the $20 \mathrm{~s}, 50 \mathrm{~s}$, and $80 \mathrm{~s}$, respectively, while a decrease is expected in autumn. In Dumkauli station, the increase is expected in spring seasons and the expected decrease in winter and autumn precipitation (Fig. 3g, 3h, and 3i). Like RCP2.6, increasing/decreasing percentage change in mean winter/spring precipitation during the $20 \mathrm{~s}$, 50s, and $80 \mathrm{~s}$ was observed under RCP4.5 and RCP8.5 scenarios in Jomsom. Baglung and Dumkauli stations also showed similar patterns under RCP4.5 and RCP8.5 scenarios for all periods. Under RCP2.6, there was an increase in precipitation during the spring season in both stations and decreased precipitation during autumn at Baglung and during winter and autumn seasons in Dumkauli station.

The mean annual precipitation prediction under RCP2.6 at Jomsom (arid region) station would increase by $14.4 \%$, $18.9 \%$, and $17.2 \%$ for future periods $20 \mathrm{~s}, 50 \mathrm{~s}$, and $80 \mathrm{~s}$, respectively (Fig. 3a). For Baglung (sub-humid region) station, the precipitation changes will be $8.27 \%, 8.67 \%$, and $14.05 \%$ for future periods $20 \mathrm{~s}, 50 \mathrm{~s}$, and $80 \mathrm{~s}$, respectively (Fig. 3d). At the same time, Dumkauli (humid-region) showed relatively less change than the other two regions. These results indicated a small change in precipitation over the humid region, whereas the significantly large change in the arid region under a highly optimistic RCP2.6 scenario during all future periods. Similar to RCP2.6, prediction under scenario RCP4.5 and RCP8.5 showed an increase in precipitation during all future periods ranging from $0.3 \%$ to $30 \%$. For instance, under scenario RCP4.5, the changes of annual mean precipitation in Jomsom (Baglung) will be 1.72 (4.4) \%, 17.19 (15.8) \%, and 30.78 (16.9) \%, while prediction for Dumkauli will be $0.3 \%, 7.08 \%$, and $15.92 \%$, for future periods 20s, 50s, and $80 \mathrm{~s}$, respectively (Figs. 3b, e, and h). Likewise, the changes of annual mean precipitation of future periods $20 \mathrm{~s}, 50 \mathrm{~s}$, and $80 \mathrm{~s}$ under RCP8.5 scenario in Jomsom will be $20.19 \%, 55.92 \%$, and $30.78 \%$, respectively (Fig. 3c); as to Baglung station, the changes will be $4.43 \%, 20.42 \%$, and $42.50 \%$, respectively (Fig. $3 f$ ), while for Dumkauli it will be $4.20 \%, 18.72 \%$, and $33.90 \%$, respectively (Fig. 3i). Overall, all three stations showed a significant increase in precipitation from low to high emission scenarios until the $21^{\text {st }}$ century.
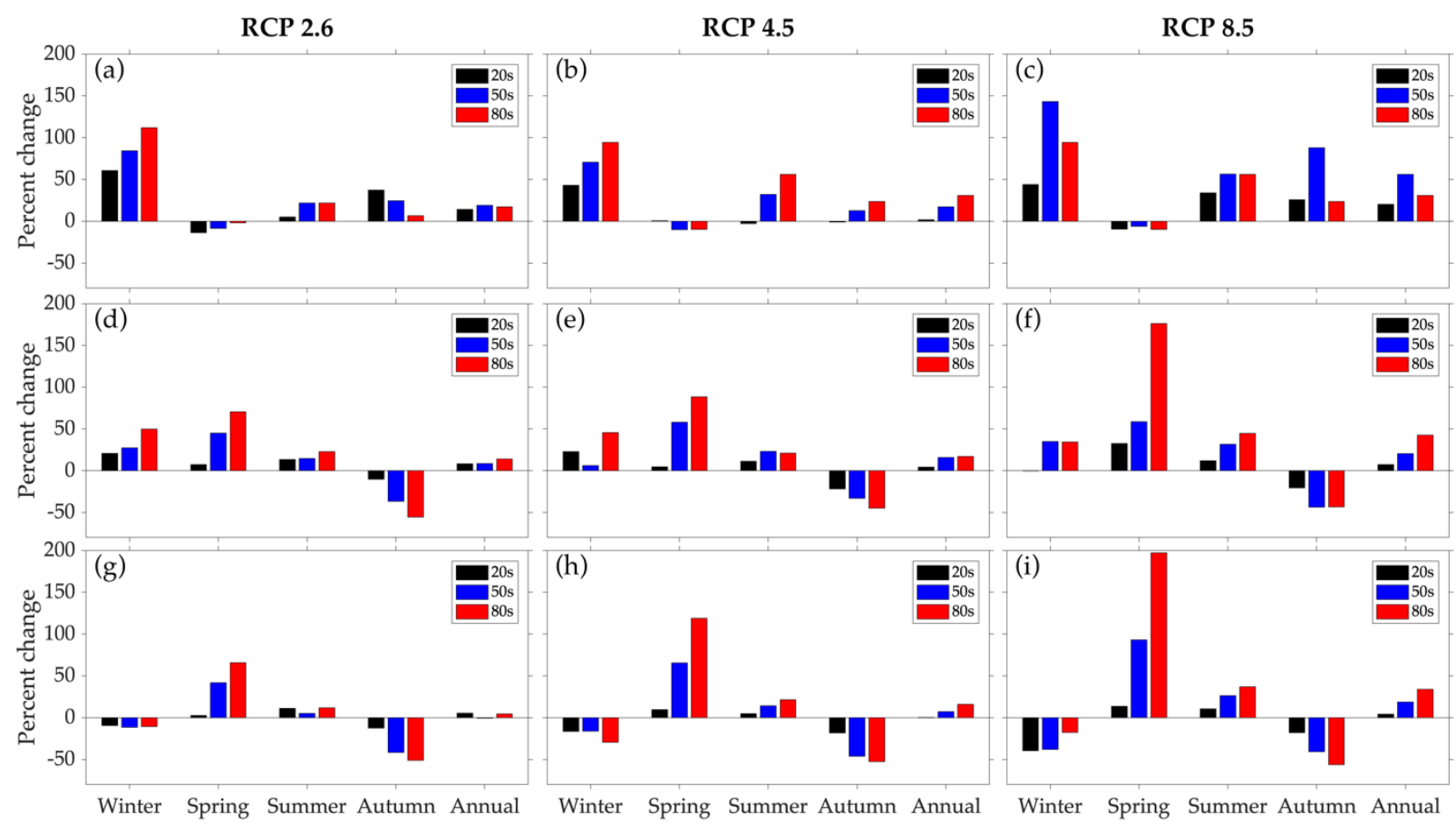

Fig. 3. Future precipitation changes in (a, b, c) Jomsom, (d, e, f) Baglung, (g, h, i) Dumkauli under different scenarios

The analysis of downscaled precipitation predicted the rise in mean annual rainfall in Gandaki Basin for the future periods $20 \mathrm{~s}, 50 \mathrm{~s}$, and $80 \mathrm{~s}$ under all scenarios in each station. Dahal et al. (2020) and Rajbhandari et al. (2018) also projected an increase in rainfall in Koshi and
Karnali, and Koshi River Basin, respectively. This increase in precipitation may be attributed to an increase in the surface temperature, which in turn may raise the rate of evaporation, leading to increased precipitation (Anandhi et al., 2008). The annual percentage increase in 
rainfall is the highest in Jomsom (arid region), followed by Baglung (sub-humid) and Dumkauli (humid), respectively. The largest change in precipitation pattern was expected in Jomsom compared to the other two regions. A similar changing scenario under $\mathrm{H} 3 \mathrm{~A} 2$ and H3B2 has been previously observed by Sigdel and Ma (2016) for Jomsom station. In contrast, Rajbhandari et al. (2018) have projected decreased rainfall in transHimalayan region of the Koshi basin. The seasonal cycle further indicated that the winter precipitation over the arid region (Jomsom) is more sensitive to climate change. Interestingly, the summer precipitation was expected to be less susceptible to future climate change than other seasons.

\section{Future changes in temperature}

This study further evaluated the change in mean monthly temperature for future periods (the 20s, 50s, and 80s) under three different RCPscenarios. The changes in $\mathrm{T}_{\max }$ and $\mathrm{T}_{\min }$ in three regions under RCP2.6, RCP4.5, and RCP8.5 are shown in Figs. 4-6. The highest increase in maximum temperature was predicted in the arid region (Jomsom) in comparison to other humid and subhumid regions (Fig. 4). The increase in $\mathrm{T}_{\max }$ was predicted from February to May in all periods. The $\mathrm{T}_{\max }$ increase in the ranges $0.6-1.41^{\circ} \mathrm{C}, 1.02-1.9^{\circ} \mathrm{C}$, and $1.8-3.01^{\circ} \mathrm{C}$ under RCP2.6 scenario (Fig. 4a), $0.2-1.2^{\circ} \mathrm{C}, 1.16-2.07^{\circ} \mathrm{C}$, and 2.12-3.18 ${ }^{\circ} \mathrm{C}$ under RCP4.5 (Fig. 4b), and $2.3-4.05^{\circ} \mathrm{C}$, 4.09-5.35 ${ }^{\circ} \mathrm{C}$, and 5.82-6.72 ${ }^{\circ} \mathrm{C}$ under RCP8.5 (Fig. 4c) in the $20 \mathrm{~s}, 50 \mathrm{~s}$, and $80 \mathrm{~s}$, respectively. The highest increase in temperature $\left(6.72^{\circ} \mathrm{C}\right)$ was anticipated in February under the RCP8.5 scenario during the $80 \mathrm{~s}$. On the contrary, substantial decreases in $\mathrm{T}_{\max }$ were expected during the summer monsoon period (June to October) under all three scenarios for future periods. The highest decrease (above $-2^{\circ} \mathrm{C}$ ) was observed in September under RCP8.5 in the 80s (Fig. 4c).

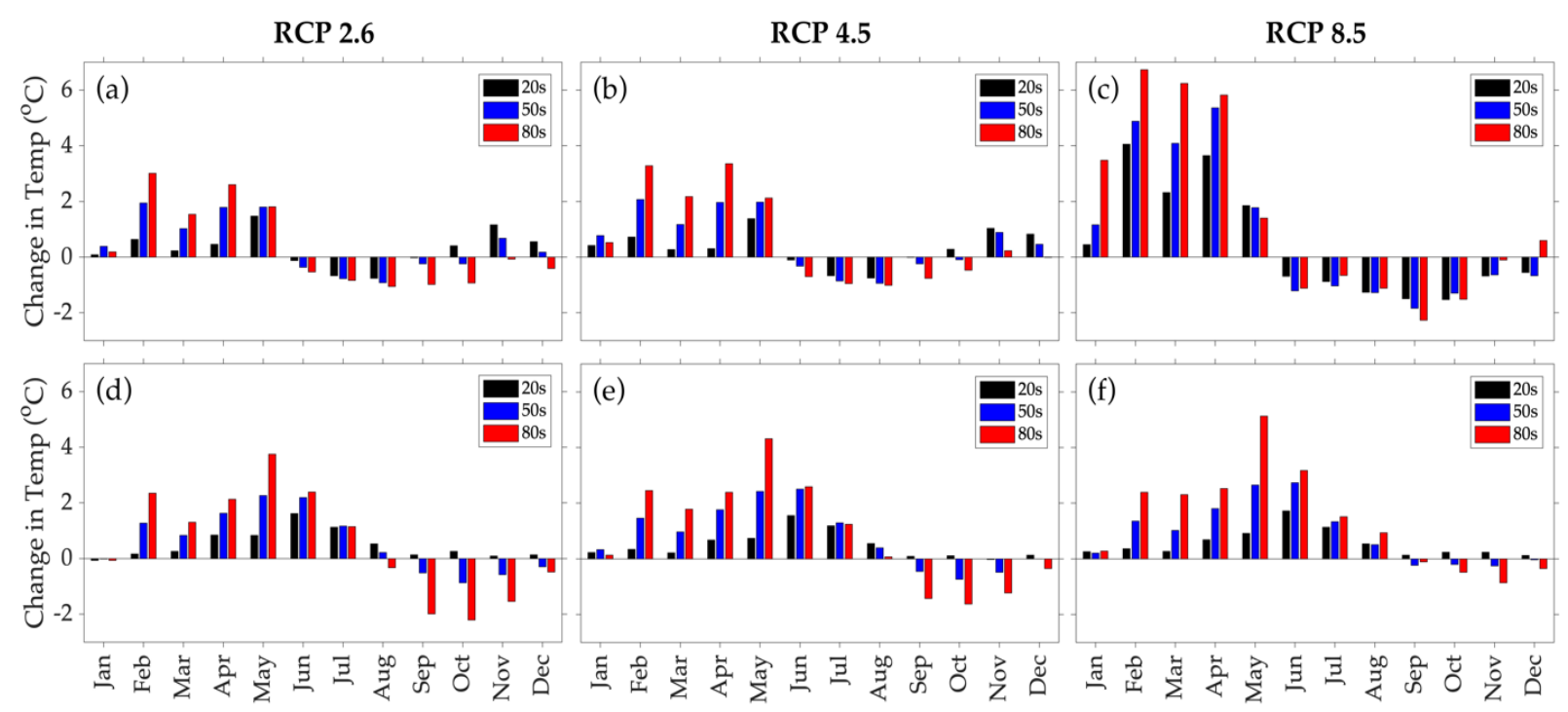

Fig. 4. Future change in $(a, b, c)$ maximum temperature $\left(T_{\max }\right)$, and $(d, e, f)$ minimum temperature $\left(T_{\min }\right)$ at Jomsom station under RCP2.6 (right panel), RCP4.5 (central panel), and RCP8.5 (left panel)

Besides Jomsom, the increase in $\mathrm{T}_{\max }$ was predicted in Baglung and Dumkauli station. In contrast to Jomsom, the increase and decrease in temperature were observed during winter and pre-monsoon months, respectively, for Baglung station (Figs. 5a, 5c, and 5e). Similarly, in Dumkauli stations $\mathrm{T}_{\max }$ increased in February and decreased in November, followed by June under all scenarios (Fig. 5). Further, the Baglung station showed similar monthly patterns as Jomsom, except for a slight increase in September (Figs. 5 and 6).

In the case of $\mathrm{T}_{\min }$, the increase and decrease were expected as observed in maximum temperature, but with different magnitude and trend (lower panel in Figs. 4-6). The greatest change in $\mathrm{T}_{\min }$ was observed at Jomsom station in all three scenarios. In contrast to $\mathrm{T}_{\max }$, an increase in $\mathrm{T}_{\min }$ was predicted for an extended period from February to August, with the highest increase in May (Fig. 4). The increase in $\mathrm{T}_{\min }$ is in the range of $0.8-1.6^{\circ} \mathrm{C}, 1.6$ $2.26^{\circ} \mathrm{C}$, and $2.12-3.74^{\circ} \mathrm{C}$ under $\mathrm{RCP} 2.6$; $0.6-1.5^{\circ} \mathrm{C}$, 1.75-2.5 $\mathrm{C}$, and $2.38-4.31^{\circ} \mathrm{C}$ under RCP4.5; and 0.6$1.7^{\circ} \mathrm{C}, 1.8-2.73^{\circ} \mathrm{C}$, and $2.52-5.13^{\circ} \mathrm{C}$ under RCP8.5 scenario for the future periods of the $20 \mathrm{~s}, 50 \mathrm{~s}$, and $80 \mathrm{~s}$, respectively.

It is worth to note that a decrease in $\mathrm{T}_{\min }$ is higher in low emission scenarios and lower in higher emission scenarios in all future periods. Similar patterns were also observed at Baglung and Dumkauli stations (lower panel in Figs. 7 and 8). Besides, both stations have followed a similar 
pattern with little change in $\mathrm{T}_{\text {min }}$ during the summer monsoon seasons under all scenarios. This feature was more prominent in Dumkauli station.

In general, mean monthly temperature scenarios showed warmer conditions in the periods of the 20s, 50s, and 80s compared with the base period (1981-2005) (Figs. 4-6), however, there was a difference in temperature change among RCP2.6, RCP4.5, and RCP8.5. Similar significant warming towards the end of the century was projected in the Koshi river basin (Rajbhandari et al., 2018) and
Marsyangdi river basin (Khadka \& Pathak, 2016). A wide range of air temperature changes in different months and under different scenarios were anticipated. The mean monthly temperature was expected to increase from January to July for all three scenarios and decrease in the later months in all regions under RCP4.5, and RCP8.5 scenarios with a slight increase were expected in RCP2.6 scenario.

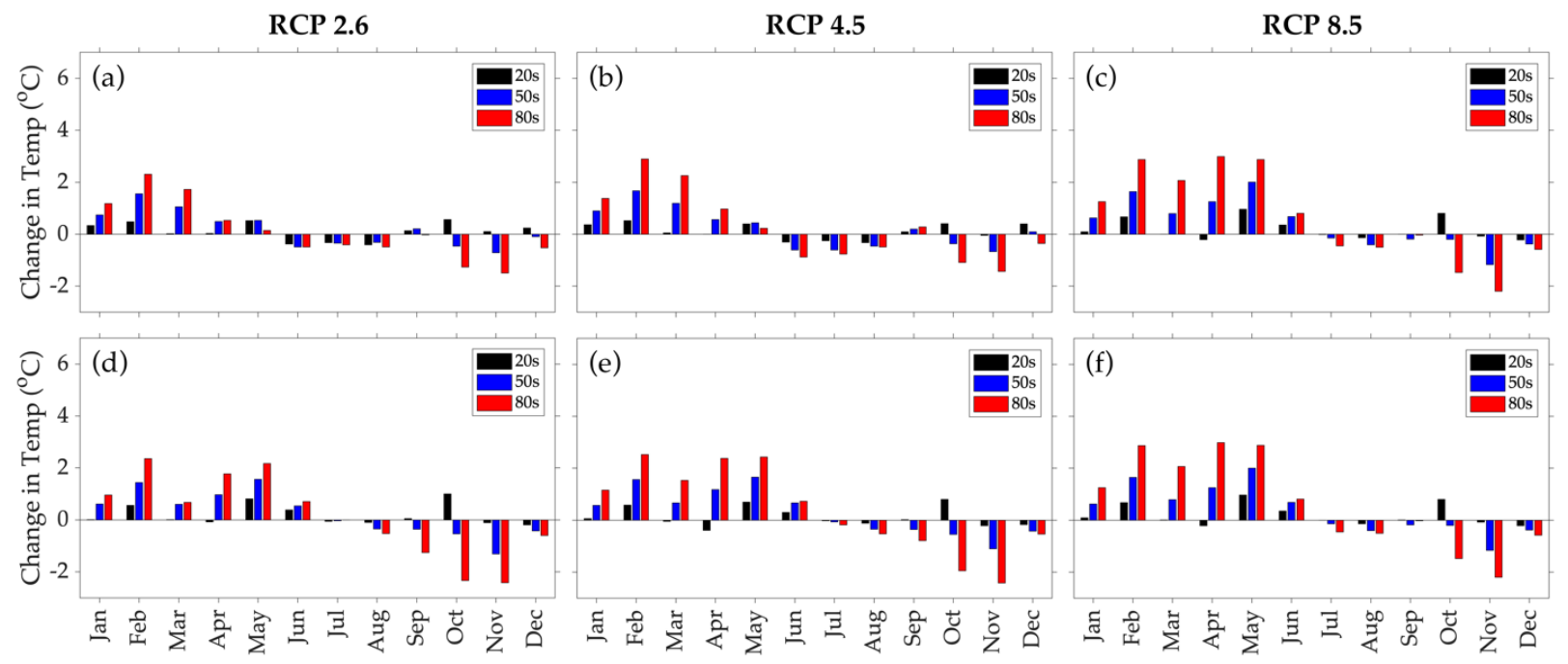

Fig. 5. Future change in $(a, b, c)$ maximum temperature $\left(T_{\max }\right)$, and $(d, e, f)$ minimum temperature $\left(T_{\min }\right)$ at $B$ aglung station under RCP2.6 (right panel), RCP4.5 (central panel), and RCP8.5 (left panel)
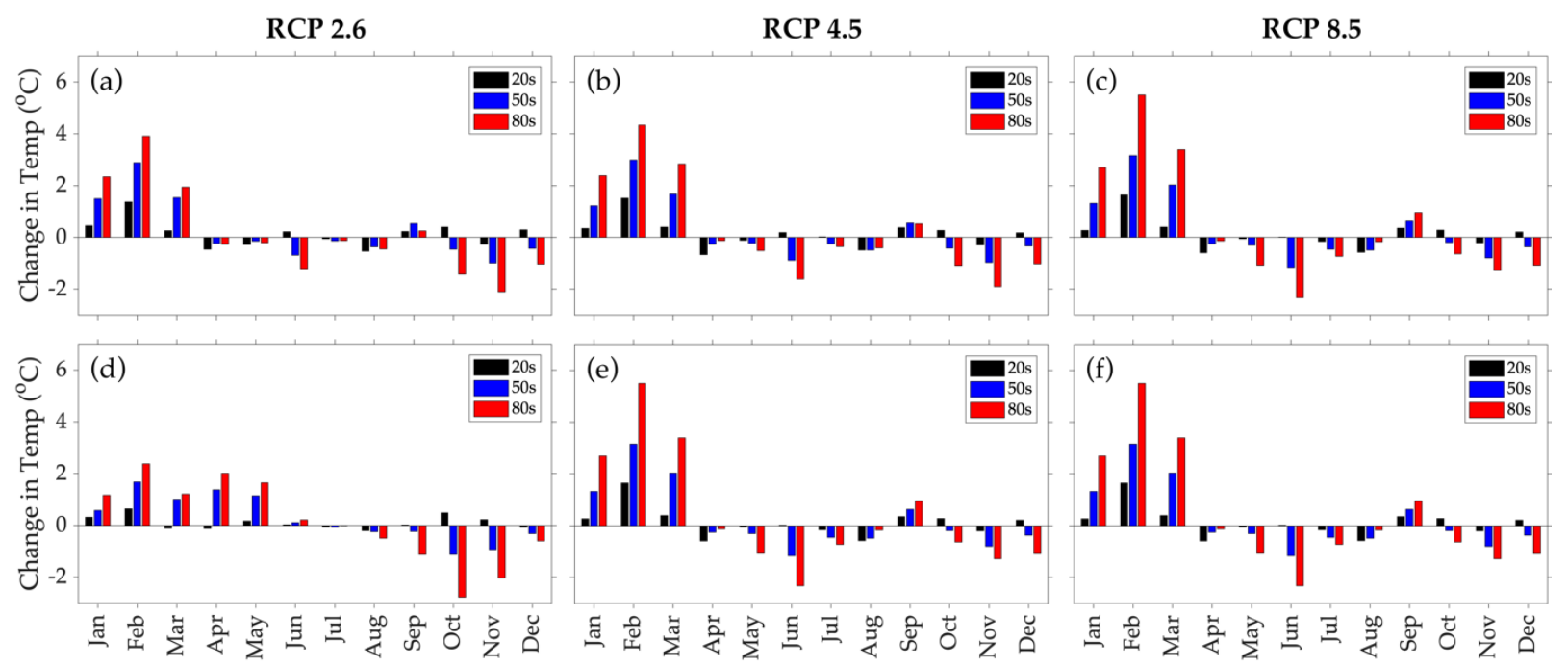

Fig. 6. Future change in (a, b, c) Maximum Temperature $\left(T_{\max }\right)$, and $(d, e, f)$ Minimum Temperature $\left(T_{\min }\right)$ at Dumkauli station under RCP2.6 (right panel), RCP4.5 (central panel), and RCP8.5 (left panel)

Further, an apparent elevation-dependent temperature change was observed in the study region, i.e., lesser/greater temperature change in the lower/higher regions. The result also showed that the most significant impact of climate change will be in the arid region
(Jomsom), which lies in the High Mountains' lee-ward side. Sigdel \& Ma (2016) have also indicated that the arid Jomsom region is more sensitive to future climate change. The increase in $\mathrm{T}_{\max }$ was high in Jomsom, followed by Dumkauli and Baglung. The maximum increase in $\mathrm{T}_{\max }$ 
was expected in February in all regions under all RCP scenarios, whereas the maximum increase in $\mathrm{T}_{\min }$ was expected in May in Jomsom and February in Baglung and Dumkauli. Similarly, a more significant change in $\mathrm{T}_{\min }$ was also observed in Jomsom than Baglung and Dumkauli regions. The study showed that the effect of climate change in minimum temperature in lower regions, i.e., Baglung and Dumkauli was less evident than Jomsom under all RCP scenarios.

\section{CONCLUSIONS}

This study applied statistical downscaling model (SDSM) to downscale the maximum temperature $\left(\mathrm{T}_{\max }\right)$, minimum temperature $\left(\mathrm{T}_{\min }\right)$, and precipitation $(\mathrm{PRECP})$ in the three different climatic regions (arid region: Jomsom, subhumid region: Baglung, and humid region: Dumkauli) across Gandaki River Basin of Nepal. Different downscaling scenarios (i.e., RCP2.6, RCP4.5, and RCP8.5) are adopted to predict future climatic changes (i.e., the 2020s, 2050s, and 2080s) based on past climatic records from 1981-2005. The significant findings are as follows:

1. The higher increase in annual precipitation is expected in the arid region (Jomsom) than Baglung and Dumkauli areas. The precipitation change was greatest in the $80 \mathrm{~s}$ in all seasons except in winter and autumn at Jomsom (highest in mid-century 50s). The greatest seasonal changes are predicted during the winter season in Jomsom-for future periods (the 20s, $50 \mathrm{~s}$, and 80s) with $60.5 \%, 84.3 \%$, and $111.9 \%$. In contrast, increase precipitation was observed during winter and spring at Baglung and during spring at Dumkauli station under all scenarios.

2. The highest increase in $T_{\max }$ and $T_{\min }$ is predicted in the arid region (Jomsom) in comparison to other humid and sub-humid regions. $\mathrm{T}_{\max }$ and $\mathrm{T}_{\min }$ may increase up to $6.72^{\circ} \mathrm{C}$ and $5.13^{\circ} \mathrm{C}$, respectively, under RCP 8.5 by the end of the $21^{\text {st }}$ century.

3. The highest increase in $\mathrm{T}_{\max }$ is expected in February for all stations. Meanwhile, an increase in $\mathrm{T}_{\min }$ is maximum in May at Jomsom and in February at other stations. Likewise, a decrease in $T_{\max }$ and $T_{\min }$ is observed in the autumn period (post monsoon) with the greatest change in Dumkauli and lowest change in Jomsom.

4. The comparison of precipitation does not show any spatial consistencies. In contrast, the mean observed $\mathrm{T}_{\max }$ and $\mathrm{T}_{\min }$ compared to simulated $\mathrm{T}_{\max }$ and $\mathrm{T}_{\min }$ showed high $R^{2}$ values. The higher correlation of mean monthly precipitation between observed and simulated values showed the applicability of using SDSM for future projection of temperature and precipitation across higher to lower Nepal's elevation regions.
5. This study will help the government and policymakers analyze and take necessary steps for prevention and minimize the losses from extreme climate events and agriculture-related disaster. Further, this study also paves the way for the study of hydrological impacts under future climate change in the three climatic zones across Nepal's Gandaki River basin.

\section{ACKNOWLEDGMENT}

The authors would like to thank the Department of Hydrology and Meteorology for providing rainfall and temperature data.

\section{REFERENCES}

Anandhi, A., Srinivas, V., Nanjundiah, R. S., \& Nagesh Kumar, D. (2008). Downscaling precipitation to river basin in India for IPCC SRES scenarios using support vector machine. International Journal of Climatology: A Journal of the Royal Meteorological Society, 28, 401-420.

Bajracharya, S. R., \& Shrestha, B. R. (2011). The status of glaciers in the Hindu Kush-Himalayan region. International Centre for Integrated Mountain Development (ICIMOD), Kathmandu.

Bhattarai, T. (2015). Flood events in Gangapur village, Banke district: An example of climate changeinduced disaster in Nepal. Journal of Institute of Science and Technology, 19(1), 79-85.

Cavalcante, R. B. L., da Silva Ferreira, D. B., Pontes, P. R. M., Tedeschi, R. G., da Costa, C. P. W., \& de Souza, E. B. (2020). Evaluation of extreme rainfall indices from CHIRPS precipitation estimates over the Brazilian Amazonia. Atmospheric Research, 238, 104879 .

Collins, M., Knutti, R., Arblaster, J., Dufresne, J.-L., Fichefet, T., Friedlingstein, P., Gao, X., Gutowski, W. J., Johns, T., \& Krinner, G. (2013). Long-term climate change: projections, commitments and irreversibility. In Climate Change 2013-The Physical Science Basis: Contribution of Working Group I to the Fifth Assessment Report of the Intergovernmental Panel on Climate Change. Cambridge University Press, pp. 1029-1136.

Dahal, P., Shrestha, M. L., Panthi, J., \& Pradhananga, D. (2020). Modeling the future impacts of climate change on water availability in the Karnali River Basin of Nepal Himalaya. Environmental Research, 185 , https://doi.org/10.1016/j.envres.2020.109430

Daly, C., Slater, M. E., Roberti, J. A., Laseter, S. H., \& Swift, L. W. (2017). High-resolution precipitation mapping in a mountainous watershed: ground truth 
for evaluating uncertainty in a national precipitation dataset. International Journal of Climatology, 37, 124-137.

Eischeid, J. K., Bruce Baker, C., Karl, T. R., \& Diaz, H. F. (1995) The quality control of long-term climatological data using objective data analysis. Journal of Applied Meteorology, 34, 2787-2795.

Faiz, M. A., Liu, D., Fu, Q., Sun, Q., Li, M., Baig, F., Li, T. and Cui, S. (2018) How accurate are the performances of gridded precipitation data products over Northeast China? Atmospheric Research, 211, 12-20.

Hamal, K., Khadka, N., Rai, S., Joshi, B. B., Dotel, J., Khadka, L., Bag, N., Ghimire, S. K., \& Shrestha, D. (2020a). Evaluation of the TRMM product for spatio-temporal characteristics of precipitation over Nepal (1998-2018). Journal of Institute of Science and Technology, 25(2), 39-48.

Hamal, K., Sharma, S., Baniya, B., Khadka, N., \& Zhou, X. (2020b). Inter-annual variability of winter precipitation over Nepal coupled with oceanatmospheric patterns during 1987-2015. Frontiers in Earth Science, $\quad 8, \quad 161$. https://doi.org/10.3389/feart.2020.00161

Hamal, K., Sharma, S., Khadka, N., Baniya, B., Ali, M., Shrestha, M. S., Xu, T., Shrestha, D., \& Dawadi, B. (2020c). Evaluation of MERRA-2 precipitation products using gauge observation in Nepal. Hydrology, 7 ,

https://doi.org/10.3390/hydrology7030040

IPCC. (2013). Climate change 2013: The physical science basis. In Stocker, T.F. et al. (Ed.), Working group I to the fifth assessment report of the intergovernmental panel on climate change (p. 222), WMO/UNEP.

https://www.ipcc.ch/site/assets/uploads/2018/03/WG 1AR5_SummaryVolume_FINAL.pdf

Kalnay, E., Kanamitsu, M., Kistler, R., Collins, W., Deaven, D., Gandin, L., Iredell, M., Saha, S., White, G., \& Woollen, J. (1996). The NCEP/NCAR 40-year reanalysis project. Bulletin of the American Meteorological Society, 77, 437-472.

Kansakar, S. R., Hannah, D. M., Gerrard, J., \& Rees, G. (2004) Spatial pattern in the precipitation regime of Nepal. International Journal of Climatology, 24, 1645-1659.

Karki, R., Hasson, S. U., Schickhoff, U., Scholten, T., \& Böhner, J. (2017). Rising precipitation extremes across Nepal. Climate, 5(1), 4. https://doi.org/10.3390/cli5010004
Karki, R., Talchabhadel, R., Aalto, J., \& Baidya, S. K. (2015). New climatic classification of Nepal. Theoretical and Applied Climatology, 125, 799-808.

Khadka, D., Babel, M. S., Shrestha, S., \& Tripathi, N. K. (2014). Climate change impact on glacier and snow melt and runoff in Tamakoshi basin in the Hindu Kush Himalayan (HKH) region. Journal of Hydrology, 511, 49-60.

Khadka, D., \& Pathak, D. (2016). Climate change projection for the marsyangdi river basin, Nepal using statistical downscaling of GCM and its implications in geodisasters. Geoenvironmental Disasters, 3, 15. https://doi.org/10.1186/s40677-0160050-0

Khadka, N., Ghimire, S. K., Chen, X., Thakuri, S., Hamal, K., Shrestha, D., \& Sharma, S. (2020). Dynamics of maximum snow cover area and snow line altitude across Nepal (2003-2018) using improved MODIS data. Journal of Institute of Science and Technology, 25(2), 17-24.

Khadka, N., Zhang, G., \& Thakuri, S. (2018). Glacial lakes in the Nepal Himalaya: Inventory and decadal dynamics (1977-2017). Remote Sensing, 10, 1913.

Klein Tank, A., Peterson, T., Quadir, D., Dorji, S., Zou, X., Tang, H., Santhosh, K., Joshi, U., Jaswal, A., \& Kolli, R. (2006). Changes in daily temperature and precipitation extremes in central and south Asia. Journal of Geophysical Research: Atmospheres, 111, D16105. https://doi.org/10.1029/2005JD006316

Koukidis, E. N., \& Berg, A. A. (2009). Sensitivity of the Statistical DownScaling Model (SDSM) to reanalysis products. Atmosphere-ocean, 47, 1-18.

Krishnamurthy, C. K. B., Lall, U., \& Kwon, H.-H. (2009). Changing frequency and intensity of rainfall extremes over India from 1951 to 2003. Journal of Climate, 22, 4737-4746.

Maharjan, S., \& Regmi, R. R. (2015). Numerical prediction of extreme precipitation over a truly complex terrain of Nepal Himalaya. Journal of Institute of Science and Technology, 20(1), 15-19.

Mahmood, R., \& Babel, M. S. (2013). Evaluation of SDSM developed by annual and monthly submodels for downscaling temperature and precipitation in the Jhelum basin, Pakistan and India. Theoretical and Applied Climatology, 113, 27-44.

Mahmood, R., \& Babel, M. S. (2014). Future changes in extreme temperature events using the statistical downscaling model (SDSM) in the trans-boundary region of the Jhelum river basin. Weather and Climate Extremes, 5, 56-66. 
MoFE. (2019) Climate change scenarios for Nepal for national adaptation plan (NAP). Ministry of Forests and Environment, Kathmandu, Nepal, 1, p. 74.

Pokharel, B., Wang, S. Y. S., Meyer, J., Marahatta, S., Nepal, B., Chikamoto, Y., \& Gillies, R. (2019). The east-west division of changing precipitation in Nepal. International Journal of Climatology, 40, 3348-3359.

Rajbhandari, R., Shrestha, A. B., Nepal, S., \& Wahid, S. (2018). Projection of future precipitation and temperature change over the transboundary Koshi River basin using regional climate model PRECIS. Atmospheric and Climate Sciences, 8, 163.

Salzmann, N., Frei, C., Vidale, P.-L., \& Hoelzle, M. (2007). The application of regional climate model output for the simulation of high-mountain permafrost scenarios. Global and Planetary Cchange, 56: 188-202.

Schneider, U., Ziese, M., Meyer-Christoffer, A., Finger, P., Rustemeier, E., \& Becker, A. (2016). The new portfolio of global precipitation data products of the global precipitation climatology centre suitable to assess and quantify the global water cycle and resources. Water Resources Assessment and Seasonal Prediction, 374, 29-34.

Sharma, S., Chen, Y., Zhou, X., Yang, K., Li, X., Niu, X., $\mathrm{Hu}, \mathrm{X} .$, \& Khadka, N. (2020a). Evaluation of GPMEra satellite precipitation products on the southern slopes of the Central Himalayas against rain gauge data. Remote Sensing, 12, 1836. https://doi.org/10.3390/rs12111836

Sharma, S., Hamal, K., Khadka, N., \& Joshi, B. B. (2020b). Dominant pattern of year-to-year variability of summer precipitation in Nepal during 1987-2015. Theoretical and Applied Climatology, 142, 10711084.

Sharma, S., Khadka, N., Hamal, K., Baniya, B., Luintel, N., \& Joshi, B. B. (2020c). Spatial and temporal analysis of precipitation and its extremities in seven provinces of Nepal (2001-2016). Applied Ecology and Environmental Sciences, 8, 64-73.

Sharma, S., Khadka, N., Hamal, K., Shrestha, D., Talchabhadel, R., \& Chen, Y. (2020d). How accurately can satellite products (TMPA and IMERG) detect precipitation patterns, extremities, and drought across the Nepalese Himalaya? Earth and Space Science, 7, e2020EA001315. https://doi.org/10.1029/2020ea001315

Sharma, S., Khadka, N., Nepal, B., Ghimire, S. K., Luintel, N., \& Hamal, K. (2021). Elevation dependency of precipitation over southern slope of Central Himalaya. Jalawaayu, 1, 1-14.

Shrestha, A. B., Bajracharya, S. R., Sharma, A. R., Duo, C., \& Kulkarni, A. (2017). Observed trends and changes in daily temperature and precipitation extremes over the Koshi River basin 1975-2010. International Journal of Climatology, 37. https://doi.org/1066-1083. 10.1002/joc.4761

Shrestha, A. B., Wake, C. P., Dibb, J. E., \& Mayewski, P. A. (2000). Precipitation fluctuations in the Nepal Himalaya and its vicinity and relationship with some large scale climatological parameters. International Journal of Climatology, 20, 317-327.

Shrestha, D., Sharma, S., Hamal, K., Jadoon, U. K., \& Dawadi, B. (2021). Spatial distribution of extreme precipitation events and its trend in Nepal. Environmental Sciences, 9, 58-66.

Shrestha, D., Singh, P., \& Nakamura, K. (2012). Spatiotemporal variation of rainfall over the central Himalayan region revealed by TRMM precipitation radar. Journal of Geophysical Research: Atmospheres, 117. https://doi.org/10.1029/2012jd018140

Sigdel, M., \& Ma, Y. (2016). Evaluation of future precipitation scenario using statistical downscaling model over humid, subhumid, and arid region of Nepal- a case study. Theoretical and applied climatology, 123: 453-460.

Talchabhadel, R., \& Karki, R. (2019). Assessing climate boundary shifting under climate change scenarios across Nepal. Environmental Monitoring and Assessment, $\quad 191$ : 520. https://doi.org/10.1007/10661-019-7907-0

WECS. (2014). Study of impact of climate change in water induced disasters in river basins and their management. Water and Energy Commission Secretariat (WECS), Kathmandu, Nepal.

Wilby, R. L., \& Dawson, C. W. (2007). SDSM 4.2-A decision support tool for the assessment of regional climate change impacts. User Manual (p. 94). https://sdsm.org.uk/SDSMManual.pdf

Wilby, R. L., Dawson, C. W., \& Barrow, E. M. (2002). SDSM- a decision support tool for the assessment of regional climate change impacts. Environmental Modelling \& Software, 17, 145-157.

Williams, T., Tarawali, S., Hiernaux, P., \& Fernández Rivera, S. (2004). Sustainable crop-livestock production for improved livelihoods and natural resource management in West Africa. eds. 
$\begin{array}{llllllll}\text { A } & \mathbf{P} & \mathbf{P} & \mathbf{E} & \mathbf{N} & \mathbf{D} & \mathbf{I} & \mathbf{X}\end{array}$

Table A1. Selected predictors for three regions over the Gandaki River Basin

\begin{tabular}{|l|l|l|l|}
\hline \multirow{2}{*}{ Stations } & \multicolumn{3}{|c|}{ Predictors } \\
\cline { 2 - 4 } & \multicolumn{1}{|c|}{$\mathrm{T}_{\max }$} & \multicolumn{1}{c|}{$\mathrm{T}_{\min }$} & \multicolumn{1}{c|}{ PRECP } \\
\hline & ncepmslpgl.dat & ncepmslpgl.dat & ncepp5_fgl.dat \\
\hline & ncepp5_zgl.dat & ncepp1_ugl.dat & ncepshumgl.dat \\
\hline & ncepp500gl.dat & ncepp5_zgl.dat & \\
\hline & ncepp5zhgl.dat & ncepp500gl.dat & \\
\hline & ncepshumgl.dat & ncepp850gl.dat & \\
\hline & nceptempgl.dat & ncepshumgl.dat & \\
\hline & & nceptempgl.dat & \\
\hline & ncepp1_zgl.dat & ncepp5_ugl.dat & ncepp1_zgl.dat \\
\hline & ncepp5_fgl.dat & ncepp5_vgl.dat & ncepp1zhgl.dat \\
\hline & ncepprcpgl.dat & ncepp850gl.dat & nceps850gl.dat \\
\hline & ncepshumgl.dat & nceptempgl.dat & nceptempgl.dat \\
\hline & nceptempgl.dat & & \\
\hline & ncepp1zhgl.dat & ncepp5_zgl.dat & ncepp1_vgl.dat \\
\hline & ncepp5_zgl.dat & ncepprcpgl.dat & ncepp1zhgl.dat \\
\hline & ncepp500gl.dat & nceps500gl.dat & ncepp5_fgl.dat \\
\hline & ncepshumgl.dat & ncepshumgl.dat & ncepshumgl.dat \\
\hline & nceptempgl.dat & nceptempgl.dat & nceptempgl.dat \\
\hline
\end{tabular}

